\title{
A lateral flow-based portable platform for determination of reproductive status of cattle
}

\author{
M. Masello, ${ }^{1} \odot$ Z. Lu, ${ }^{2}$ D. Erickson, ${ }^{2}$ J. Gavalchin, ${ }^{1} \odot$ and J. O. Giordano ${ }^{1 *}$ (]) \\ ${ }^{1}$ Department of Animal Science, Cornell University, Ithaca, NY 14853 \\ ${ }^{2}$ Sibley School of Mechanical and Aerospace Engineering, Cornell University, Ithaca, NY 14853
}

\begin{abstract}
Our objective was to develop and validate a tool integrating a disposable fluorescence-based lateral flow immunoassay (LFIA) coupled with a portable imaging device for estimating circulating plasma concentrations of progesterone (P4). First, we developed and optimized a competitive LFIA test strip to measure P4 in bovine plasma. The LFIA design included a sample pad, a conjugate pad that stores R-phycoerythrin-antiP4 conjugates, a glass-fiber spacer pad, a nitrocellulose membrane with printed test and control lines, and a cellulose-fiber absorbent pad. To perform a test, $20 \mu \mathrm{L}$ of plasma and $50 \mu \mathrm{L}$ of running buffer were added on the sample pad. After 3 min, $45 \mu \mathrm{L}$ of running buffer was added to initiate sample flow. After allowing 15 min to stabilize the colorimetric signal, strips were introduced in an LFIA portable reader wirelessly linked to a laptop to determine $\mathrm{P} 4$ concentration based on test-to-controlline signal ( $\mathrm{T} / \mathrm{C}$ ratio). In a series of experiments (n $=6$ ), the ability of the LFIA to differentiate plasma samples with $\geq 1$ or $<1 \mathrm{ng} / \mathrm{mL}$ of $\mathrm{P} 4$ was evaluated. For each experiment, a calibration curve was constructed using plasma with known concentrations of P4 (0.1 to $3.7 \mathrm{ng} / \mathrm{mL} ; \mathrm{n}=5$ ). The resulting linear equation was then used to determine a $\mathrm{T} / \mathrm{C}$ ratio cutoff to differentiate samples with $\geq 1$ or $<1 \mathrm{ng} / \mathrm{mL}$ of $\mathrm{P} 4$. In addition, to evaluate the ability of the platform to assign samples to $\mathrm{P} 4$ concentration groups without a calibration curve for individual batches, we performed a receiver operating characteristic analysis to identify a single cutoff value for $\mathrm{T} / \mathrm{C}$ ratio that could potentially be used for all batches. Overall, calibration curves showed a linear relationship between $\mathrm{T} / \mathrm{C}$ ratio and $\mathrm{P} 4$ levels (mean coefficient of determination $=0.74$; range 0.42 to 0.99 ). Next, plasma samples from lactating dairy cows $(\mathrm{n}=$ 58) were tested in triplicate to determine the ability of the LFIA system to differentiate plasma samples with
\end{abstract}

Received August 29, 2019.

Accepted January 27, 2020.

*Corresponding author: jog25@cornell.edu $\geq 1$ or $<1 \mathrm{ng} / \mathrm{mL}$ of $\mathrm{P} 4$ using a RIA for $\mathrm{P} 4$ as reference test. Overall, the LFIA assay correctly classified $90 \%$ of the samples, with $97 \%$ sensitivity, $83 \%$ specificity, $85 \%$ positive predictive value, and $96 \%$ negative predictive value. Agreement between the tests was substantial (kappa $=0.79 ; 95 \%$ confidence interval 0.64 to 0.95 ). When using a single cutoff value for $\mathrm{T} / \mathrm{C}$ ratio selected by receiver operating characteristic analysis, sensitivity and specificity to determine CL presence were 97 (95\% confidence interval 82 to 99 ) and $79 \%$ (95\% confidence interval 60 to 92), respectively. These data suggest that the developed portable LFIA system can accurately differentiate plasma samples with $\geq 1$ or $<1 \mathrm{ng} / \mathrm{mL}$ of $\mathrm{P} 4$. Key words: lateral flow immunoassay, progesterone concentration determination, reproductive status, cattle

\section{INTRODUCTION}

Reproductive management of cattle is critical to the profitability and sustainability of both dairy (Giordano et al., 2012) and beef (White et al., 2015) cattle operations. Therefore, multiple management practices are used by farms to optimize reproductive performance and simplify management of females. Among others, an important practice is the determination of the reproductive status of cows including estrus, pregnancy, nonpregnancy, and anovulation. In addition, for some commercial farms determination of the reproductive status of cows also includes defining the presence or absence of a functional corpus luteum (CL) at the time of nonpregnancy diagnosis or during synchronization of ovulation protocols for timed AI. Although several methods and technologies are available to determine the reproductive status of cows, this can be either fully or partially accomplished through estimation of circulating concentrations of the steroid hormone progesterone (P4) produced by the CL. Determination of circulating concentrations of $\mathrm{P} 4$ can be used to confirm estrus (Friggens et al., 2008), as a method for nonpregnancy diagnosis (Waldmann and Raud, 2016; Wilsdorf et al., 2016), determine resumption and cessation of ovarian cyclicity (Galvão et al., 2010), confirm luteal regression 
and ovulation in synchronization of ovulation protocols (Barletta et al., 2018), and assign cows to hormonal treatments for synchronization of ovulation (McArt et al., 2010; Wijma et al., 2018). Unfortunately, decisionmaking based on accurate detection and quantification of P4 in bodily fluids (i.e., blood or milk) of cattle is not easily accomplished or cost effective for most commercial farms. Sophisticated equipment to conduct P4 testing based on assays in laboratory or farm settings are available (Skenandore et al., 2017; Adriaens et al., 2018; Bruinjé and Ambrose, 2019) but are not easily accessible to all farms due to cost, logistics of implementation, or both. Conversely, low-cost systems are available but they may not be sufficiently accurate or practical for their intended use (Posthuma-Trumpie et al., 2009; Waldmann and Raud, 2016). Thus, onfarm determination of the reproductive status of cows such as nonpregnancy, anovulation, and presence of a functional CL on the ovaries generally depends on veterinarian or farm personnel-administered exams, either by transrectal palpation or ultrasonography of the reproductive organs. A disadvantage of these methods includes requiring the expertise of highly qualified technicians and expensive equipment, which may problematic for farms located in areas where veterinary support is scarce or for farms that are unable to cover the costs of these exams. In addition, some of the methods available and widely used (i.e., transrectal palpation; NAHMS, 2018) may be less accurate than desired. For example, the reported accuracy of rectal palpation to determine the presence of a functional CL ranged from 57 to $70 \%$ (Bicalho et al., 2008).

Lateral flow immunoassays (LFIA) are gaining widespread use as rapid, point-of-care diagnostic tools for medical and veterinary applications (Tisone and O'Farrell, 2009; Sajid et al., 2015). Generally, LFIA tests are inexpensive and easy to conduct, which makes them an appealing tool for use in reproductive management of cattle. Attempts to develop LFIA tests for P4 determination have been previously reported (Waldmann and Raud, 2016; Xu et al., 2016; Nakami et al., 2017), but these have drawbacks that seem to preclude their widespread use. For instance, most of the developed LFIA for P4 depend on the subjective interpretation of assay results by the user, which may lead to improper interpretation of results (Waldmann and Raud, 2016). In addition, some of the previously developed LFIA systems (Xu et al., 2016; Nakami et al., 2017) were not designed to differentiate samples within a narrow range of $\mathrm{P} 4$ concentrations, in particular around $1 \mathrm{ng} / \mathrm{mL}$, which is the most commonly used cutoff to classify cows in relevant reproductive statuses (Ginther et al., 2010; Stevenson, 2019).
Thus, our primary objective was to develop a system integrating a disposable fluorescence-based LFIA combined with a fluorescence portable imaging device to estimate circulating concentrations of P4. Once developed, our objective was to validate our platform and its accuracy for differentiation of bovine plasma samples with $\geq 1$ or $<1 \mathrm{ng} / \mathrm{mL}$ of $\mathrm{P} 4$. This cutoff was selected because it is commonly used in research and in practice to estimate the presence of a putative functional CL in cattle (Ginther et al., 2010; Stevenson, 2019), which can be used as the sole method or as an aid to determine the reproductive status of cattle. In terms of performance, we aimed to achieve at least $90 \%$ accuracy for differentiation of cows with $\geq 1$ or $<1 \mathrm{ng} / \mathrm{mL}$ of $\mathrm{P} 4$, and substantial interrater agreement (i.e., kappa value of 0.61 to 0.80 ) with a RIA for P4 for classification of plasma samples in groups of $\mathrm{P} 4 \geq 1$ or $<1 \mathrm{ng} / \mathrm{mL}$.

\section{MATERIALS AND METHODS}

\section{Reagents and Materials}

R-Phycoerythrin (RPE) fluorophore and reagents (LL-modifier and LL-quencher) used for antibody-RPE conjugate preparation were purchased from Innova Biosciences Ltd. (Lightning-Link Conjugation Kit, Cambridge, UK). Synthetic P4 conjugated to BSA (P4-BSA) was purchased from Aviva Systems Biology (San Diego, CA). Mouse monoclonal antibodies to P4 (P4Ab) were purchased from Hytest Ltd. (Turku, Finland). Goat anti-mouse antibody, amine-free PBS buffer at $0.01 M \mathrm{pH}$ 7.4, Tween 20, BSA, borate buffer, and sucrose were acquired from Sigma-Aldrich (St. Louis, MO). Glass fiber conjugate and spacer pads $(300 \times 5 \mathrm{~mm})$, High Flow Plus 180 membrane cards $(300 \times 60 \mathrm{~mm})$, and cellulose fiber pads for sample and absorbent pads $(300 \times 20 \mathrm{~cm})$ were acquired from EMD-Millipore (Billerica, MA).

\section{Progesterone LFIA Architecture and Principles}

The P4 LFIA test strip was designed to perform a competitive type immunoassay. Briefly, our design (Figure 1A) includes a sample pad, a conjugate pad that stores the RPE-P4Ab conjugates, a spacer pad, a nitrocellulose membrane with printed test (P4-BSA), and control lines (anti-mouse antibodies), and an absorbent pad at the end of the strip to collect any waste from the assay. The sample and conjugate pads are designed to collect and incubate the sample with the RPE-P $4 \mathrm{Ab}$ conjugates, respectively. The spacer pad is designed to prevent the sample and RPE-P $4 \mathrm{Ab}$ mixture from flowing through the nitrocellulose membrane 
A

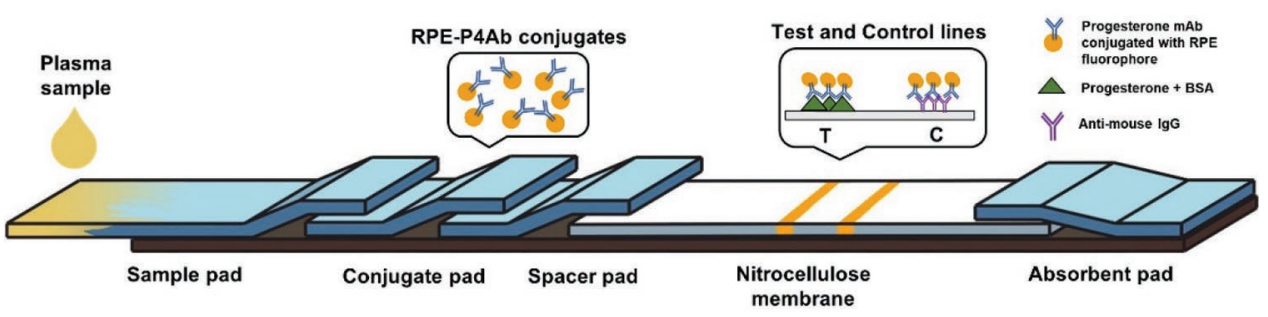

B

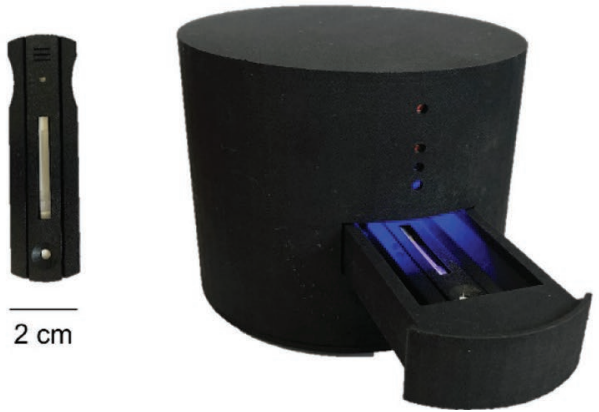

Figure 1. (A) Architecture of the lateral flow immunoassay (LFIA) test strip for progesterone (P4). The LFIA design includes a sample pad, a conjugate pad that stores R-phycoerythrin-anti-P4 conjugates (RPE-P4Ab), a spacer pad, a nitrocellulose membrane with printed test (progesterone + BSA) and control (anti-mouse antibody) lines, and an absorbent pad at the end of the strip to collect any waste from the assay. (B) Lateral-flow immunoassay test strip housed in a plastic cassette and the TIDBIT reader, a portable fluorescence reader previously described in Lu et al. (2017).

before sample flow is initiated. During incubation, the sample rehydrated the RPE-P4Ab conjugates, which then interacted with the $\mathrm{P} 4$ present in the sample. This competitive interaction determined the availability of RPE-P4Ab conjugates to bind with P4-BSA and antimouse IgG immobilized at the test and control lines, respectively.

\section{Antibody-RPE Conjugate Pad Preparation}

Monoclonal anti-P4 antibodies were conjugated with the RPE fluorophore by following the protocol provided in the Lightning-Link conjugation kit. First, to achieve a 1:1 mAb:RPE conjugation molar ratio (recommended by manufacturer), $10 \mu \mathrm{g}$ of $\mathrm{P} 4 \mathrm{Ab}$ was diluted to 1 $\mathrm{mg} / \mathrm{mL}$ in $1 \times$ PBS before mixing it with $1 \mu \mathrm{L}$ of LLmodifier reagent. Next, $10 \mu \mathrm{g}$ of RPE was re-suspended in the solution and incubated for $3 \mathrm{~h}$ in a light-free environment at room temperature $\left(20\right.$ to $\left.25^{\circ} \mathrm{C}\right)$. During incubation, the $\mathrm{P} 4 \mathrm{Ab}$ attached to the surface of $\mathrm{RPE}$ via covalent bonding. After incubation, $1 \mu \mathrm{L}$ of LLquencher reagent was added to the conjugates, which were then stored at $4^{\circ} \mathrm{C}$ in the dark until use. Before application into the conjugate pad, conjugates were mixed and diluted 400 times in conjugate buffer $(2 \mathrm{~m} M$ borate buffer with $5 \%$ sucrose). On each test strip, $3 \mu \mathrm{L}$ of the RPE-P4Ab conjugates was applied.

\section{Progesterone LFIA Strip Assembly}

High Flow Plus 180 membrane cards were used as the base layer of the LFIA test strips. The membrane cards have a 2-mm clear polyester film backing that contains a nitrocellulose membrane and the adhesive sections to attach the sample, conjugate, spacer, and absorbent pads. We chose the membrane with a slow capillary flow rate $(45 \mathrm{~s} / \mathrm{cm})$ to maximize the reaction time between the RPE-P4Ab conjugates and the analytes immobilized on the nitrocellulose membrane. For the test and control lines, P4-BSA and anti-mouse IgG were diluted to 1.5 and $0.3 \mathrm{mg} / \mathrm{mL}$, respectively, in $1 \times$ PBS and dispensed onto the nitrocellulose membrane using an automated Lateral Flow Reagent Dispenser (ClaremontBio Solutions, Upland, CA) and a dual syringe pump (Legato 200, ClaremontBio Solutions). The dual syringe pump operated at a flow rate of $6.4 \mu \mathrm{L} /$ min to ensure $1 \mathrm{~mm}$ of line width. Subsequently, membrane cards were dried in an incubator for a minimum of $8 \mathrm{~h}$ at $37^{\circ} \mathrm{C}$. Once membranes were dried, they were stored in a humidity-controlled $(<10 \%$ relative humidity) chamber at room temperature until use. The final assay was assembled by first applying the spacer pad onto the adhesive part of the nitrocellulose membrane card, followed by the conjugate and sample pads. Next, a cellulose fiber pad was attached to the other end of 
the nitrocellulose membrane to serve as the absorbent pad. To ensure a continuous sample flow path across the test strip, all pads were laminated with a $2 \mathrm{~mm}$ overlap. The final step was to cut the membrane card into individual 4-mm strips using a paper trimmer (Dahle North America Inc., Peterborough, NH), which were then sealed and stored with silica gel desiccants at $4^{\circ} \mathrm{C}$ in the dark until use.

\section{LFIA Operation Protocol}

To perform a test, first $20 \mu \mathrm{L}$ of bovine plasma and $50 \mu \mathrm{L}$ of running buffer $(1 \times$ TBS with $1 \%$ BSA, $1.5 \%$ Tween 20 , and $0.1 \%$ sodium azide) were added on the sample pad and strips were placed in a light-free environment for $3 \mathrm{~min}$. Then $45 \mu \mathrm{L}$ of running buffer was added to the sample pad to initiate flow. After allowing $15 \mathrm{~min}$ for the fluorescent signal to develop, the test strip was inserted into the TIDBIT (Figure 1B), a portable fluorescence reader previously described in Lu et al. (2017). Briefly, the TIDBIT consists of an integrated optical sensor platform designed to detect and capture the fluorescent signal displayed on the test strips. It is equipped with 6 blue light-emitting diodes covered by band-pass optical filters centered at the excitation wavelength required for the RPE fluorophore (i.e., $\sim 488 \mathrm{~nm}$ ). Once developed, the fluorescent signal is captured by a 5-megapixel 1080p HD CMOS camera (Raspberry Pi, Cambridge, UK) fitted with a focusing lens. To interpret and display the results, output images generated by the TIDBIT are wirelessly transferred to a standard laptop. After each test, results are stored in both the TIDBIT reader and the laptop, and all previous results could be accessed at any time.

Output images generated by the reader were then analyzed to determine test-to-control-line signal (T/C) ratio. Intensity of the test and control lines were quantified by using the Plot Profile option of the image processing software, ImageJ (Schneider et al., 2012). Briefly, the Plot Profile option displays a 2-dimensional graph of the intensities of pixels along a rectangular section, where the $\mathrm{x}$-axis represents the horizontal distance through the selection and the y-axis represents the vertically averaged pixel intensity. Once the plots were generated, the straight line selection tool was used to measure peak intensities corresponding to the test and control line regions.

\section{Assay Performance in Bovine Plasma Samples}

Bovine plasma samples $(\mathrm{n}=58)$ were used to evaluate the ability of the LFIA test strips to differentiate samples with $\geq 1$ or $<1 \mathrm{ng} / \mathrm{mL}$ of $\mathrm{P} 4$. Stored plasma samples obtained from previous work (Masello et al., 2020) were used to evaluate the ability of the LFIA system to differentiate samples with $\geq 1$ or $<1 \mathrm{ng} / \mathrm{mL}$ of P4. Briefly, blood samples ( $\sim 8$ to $9 \mathrm{~mL}$ ) were collected from lactating Holstein cows by puncture of the caudal vein or artery using evacuated tubes containing EDTA. After collection, samples were placed in crushed ice and transported to the laboratory for further processing. Samples were centrifuged at $2,000 \times g$ for $20 \mathrm{~min}$ at $4^{\circ} \mathrm{C}$. Plasma samples were harvested and transferred to Eppendorf vials for storage at $-20^{\circ} \mathrm{C}$ until assayed. A commercial solid-phase, no-extraction RIA (Immuchem Coated Tube, MP Biomedicals, Costa Mesa, CA) for P4 was used as the reference test and to classify samples based on a $1 \mathrm{ng} / \mathrm{mL}$ of P4 cutoff. Six batches of test strips were manufactured to perform 6 independent experiments (i.e., one batch per experiment). For each experiment, a calibration curve was constructed using 5 plasma samples with known concentrations of P4 (0.1 to $3.7 \mathrm{ng} / \mathrm{mL}$ ). For calibration sample selection, we ensured that at least one sample was within each one of the following $\mathrm{P} 4$ ranges: $<0.1 \mathrm{ng} / \mathrm{mL}$ (limit of detection of the RIA), 0.1 to $1.0 \mathrm{ng} / \mathrm{mL}, 1.1$ to $1.4 \mathrm{ng} / \mathrm{mL}$, and 1.5 to $4.0 \mathrm{ng} / \mathrm{mL}$. The range of $\mathrm{P} 4$ concentrations in the calibration curve is representative of the range observed for lactating Holstein cows during the estrous cycle and pregnancy (Hankele et al., 2020). Samples with $>4 \mathrm{ng} / \mathrm{mL}$ of $\mathrm{P} 4$ were not included because the lesser practical value of accurate quantification of $\mathrm{P} 4$ concentrations when circulating concentrations of $\mathrm{P} 4$ are $>4 \mathrm{ng} / \mathrm{mL}$. To generate a linear calibration curve, each calibration sample was tested in triplicate and the resulting average $\mathrm{T} / \mathrm{C}$ ratio was plotted against $\mathrm{P} 4$ concentrations from the reference test. The linear regression equation was then used to determine the $\mathrm{T} / \mathrm{C}$ ratio cutoff to differentiate plasma samples with $\geq 1$ or $<1 \mathrm{ng} / \mathrm{mL}$ of $\mathrm{P} 4$ (i.e., the $\mathrm{T} / \mathrm{C}$ ratio corresponding to $1 \mathrm{ng} / \mathrm{mL}$ of $\mathrm{P} 4)$. This $\mathrm{T} / \mathrm{C}$ ratio was used to evaluate assay performance by serving as a cutoff value for the classification of the 58 bovine plasma samples ( $\sim 10$ for each experiment). To have an equal number of positive and negative samples, stock plasma samples were first classified as negative $(<1 \mathrm{ng} / \mathrm{mL})$ or positive $(\geq 1 \mathrm{ng} /$ $\mathrm{mL}$ ). Within each category, we then randomly selected 5 samples. All samples were tested in triplicate and in random order. Experiments were conducted by a single technician who was blinded to $\mathrm{P} 4$ concentrations.

\section{Statistical Analyses}

The main outcome of interest for this study was to evaluate the ability of our system based on the LFIA test strips to correctly differentiate plasma samples 
with $\geq 1$ or $<1 \mathrm{ng} / \mathrm{mL}$ of $\mathrm{P} 4$. To evaluate assay performance, we created a $2 \times 2$ frequency table based on the following criteria:

- True positive $=$ positive LFIA test strip outcome (i.e., $\mathrm{T} / \mathrm{C}$ ratio lower than the estimated threshold for $\mathrm{P} 4 \geq 1 \mathrm{ng} / \mathrm{mL}$ ) and $\mathrm{P} 4 \geq 1 \mathrm{ng} / \mathrm{mL}$ by RIA.

- False positive $=$ positive LFIA test strip outcome and $\mathrm{P} 4<1 \mathrm{ng} / \mathrm{mL}$.

- True negative $=$ negative LFIA test strip outcome (i.e., $\mathrm{T} / \mathrm{C}$ ratio greater than the estimated threshold for $\mathrm{P} 4<1 \mathrm{ng} / \mathrm{mL}$ ) and $\mathrm{P} 4<1 \mathrm{ng} / \mathrm{mL}$ by RIA.

- False negative $=$ negative LFIA test strip outcome and $\mathrm{P} 4 \geq 1 \mathrm{ng} / \mathrm{mL}$.

This frequency table was then used to estimate the overall sensitivity, specificity, positive predictive value, negative predictive value, and accuracy of the LFIA test strips. Confidence intervals and tests for these statistics were computed using the "exact binomial" option of the PROC FREQ of SAS (version 9.4, SAS Institute Inc., Cary, NC). For each statistic, an exact test was performed under the null hypothesis that the proportion equals 0.5 .

To calculate the coefficient of variation for each sample, the standard deviation was divided by the mean $\mathrm{T} / \mathrm{C}$ ratio corresponding to the 3 replicates of each one of the samples.

The level of agreement between LFIA test trips and RIA (reference test) to differentiate plasma samples with $\geq 1$ or $<1 \mathrm{ng} / \mathrm{mL}$ of $\mathrm{P} 4$ was determined through calculation of the kappa value for interrater agreement obtained with FREQ procedure of SAS under the null hypothesis that kappa $=0$. A kappa of 1 indicates perfect agreement, whereas a kappa of 0 indicates no agreement (Landis and Koch, 1977). Linear models for calibration curves were generated with PROC REG of SAS including $\mathrm{T} / \mathrm{C}$ ratio as the dependent variable and known concentrations of $\mathrm{P} 4$ as the independent variable.

To examine the ability of the current LFIA-based system to differentiate plasma samples with $\geq 1$ or $<1$ $\mathrm{ng} / \mathrm{mL}$ of $\mathrm{P} 4$ without a calibration curve for individual batches, we performed receiver operating characteristic (ROC) analysis using the ROC curve option in MedCalc (version 12.5.0.0; MedCalc Software bvba, Ostend, Belgium) to identify a single cutoff value for $\mathrm{T} / \mathrm{C}$ ratio that could potentially be used for all batches. For these analyses, data did not include results from the calibration samples resulting in a total of 58 data points to generate the ROC curves.

The reference test for all analyses performed was the dichotomized P4 concentration determined by RIA using a $\mathrm{P} 4$ concentration cutoff of $1 \mathrm{ng} / \mathrm{mL}$. This cutoff was used because this is a common circulating P4 concentration value used in research or in practice to estimate the presence of a putative functional CL in cattle (Ginther et al., 2010; Stevenson, 2019).

For all analyses, variables were considered significant if $P \leq 0.05$, whereas $P$-values $>0.05$ and $\leq 0.10$ were considered a tendency.

\section{RESULTS AND DISCUSSION}

In the present study, we developed and evaluated a novel platform to estimate circulating $\mathrm{P} 4$ concentrations in bovine plasma. The platform consists of a fluorescent-based LFIA test strip, combined with a portable outcome reader that is wirelessly linked to a standard laptop or smart device. The design of the developed LFIA represents a competitive-type assay, where free $\mathrm{P} 4$ in the sample and immobilized $\mathrm{P} 4$ in the test strip compete for a limited number of antibody binding sites. We selected this format because the small size of the P4 molecule $(\sim 314 \mathrm{Da})$ precludes binding to more than one antibody simultaneously (i.e., hapten molecule). As expected of our competitive-type architecture, the T/C ratios for samples with low $\mathrm{P} 4$ levels were greater than that of samples with high P4 levels (Figures 2A to C). In Figure 2A, we present a set of typical fluorescence images acquired by the portable reader from bovine plasma samples with low, medium, and high P4 levels. Because of the competitive design, the colorimetric signal of the test line decreased as $\mathrm{P} 4$ concentration increased, whereas the colorimetric signal of the control line increased as $\mathrm{P} 4$ concentration increased. This is further illustrated in Figure 2B, where we present the profile plots of the test and control line regions created with the image processing software. These plots were used to measure the peak values of the test and control lines to calculate $\mathrm{T} / \mathrm{C}$ ratios. As expected from a competitive LFIA design, $\mathrm{T} / \mathrm{C}$ ratios decreased as $\mathrm{P} 4$ levels increased (Figure 2C).

The use of calibration curves in LFIA systems for the quantitative prediction of the concentration of an analyte has been previously reported (Lu et al., 2017; Srinivasan et al., 2018). In the present study, however, we created calibration curves to estimate a dichotomized rather than a quantitative $\mathrm{P} 4$ concentration to determine the ability of the LFIA system to differentiate bovine plasma samples with $\geq 1$ or $<1 \mathrm{ng} / \mathrm{mL}$ of $\mathrm{P} 4$ because this may be the most obvious practical value. Because of the known high variation in performance between different batches of LFIA strips (Sajid et al., 2015), we constructed a calibration curve for each experiment (i.e., one for each batch). Features and measures of variability for the calibration curves for each 
A

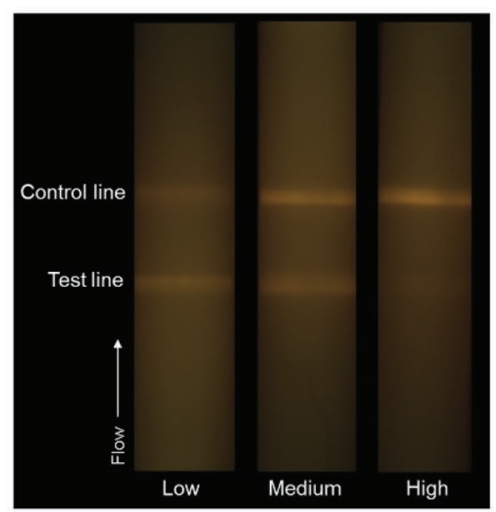

C

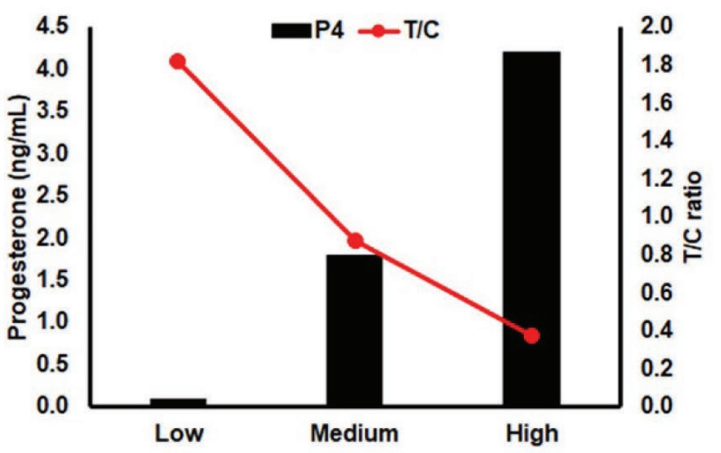

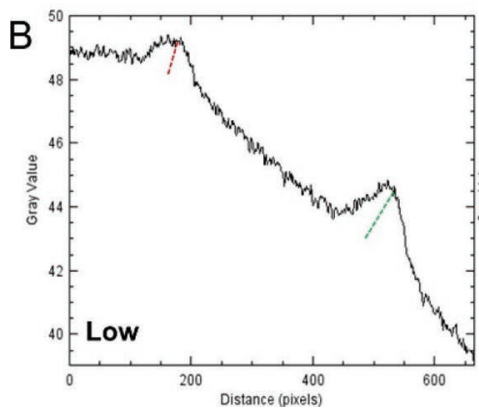
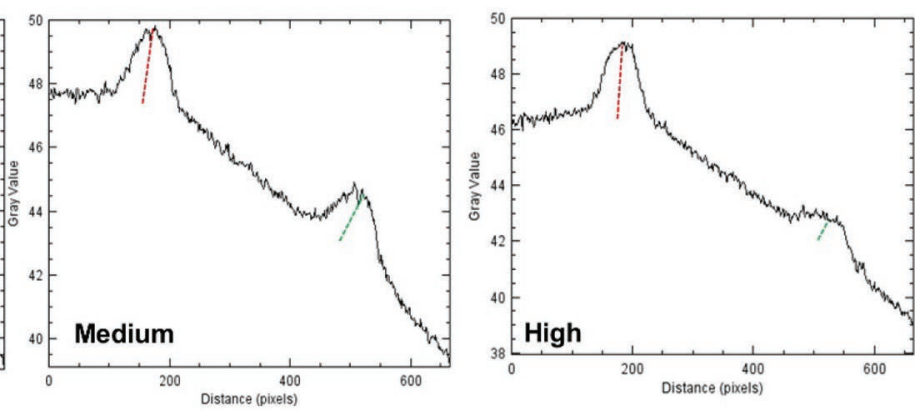

Figure 2. (A) Set of typical fluorescence images acquired by the portable reader from bovine plasma samples with low, medium, and high P4 (P4) levels. Because of the competitive design, the colorimetric signal of the test line decreased as P4 concentration increased, whereas the colorimetric signal of the control line increased as P4 concentration increased. (B) Profile plots of the test and control line regions created with the image processing software, ImageJ (Schneider et al., 2012). Green dashed line corresponds to the test line region whereas the red dashed line corresponds to the control line region. (C) Graph depicting changes in average test-to-control-line ratio (T/C; red solid line) with increasing levels of P4 (black bars). As expected from a competitive lateral flow immunoassay design, T/C ratios decreased as P4 levels increased.

experiment are presented in Table 1, and representative examples of the curves are illustrated in Figure 3 (all other curves are presented in Supplemental Figure S1; https://doi.org/10.3168/jds.2019-17517). Four out of 6 experiments showed a significant effect $(P<0.05)$ or a trend $(P=0.06)$ for the linear relationship between average $\mathrm{T} / \mathrm{C}$ ratio and $\mathrm{P} 4$ concentration (average $\mathrm{R}^{2}=$ 0.88 ; range 0.74 to 0.99 ). In contrast, calibration test results for experiments 3 and 6 did not show a statistically significant linear trend, and both curves had a suboptimal $\mathrm{R}^{2}$ (experiment $3=0.53$; experiment $6=$ 0.42 ). The lack of a linear trend and the resulting low $\mathrm{R}^{2}$ for these 2 experiments can be explained, at least in part, by the presence of outliers (i.e., observations with an absolute value of studentized residual greater than 3). Indeed, when outliers were removed (one sample for each experiment), we observed a statistically significant $(P<0.05)$ linear trend for both experiments and an increase in the $\mathrm{R}^{2}$ (experiment $3=0.94$; experiment $6=0.98$ ). In both cases, the samples removed corresponded to those within the range of 0.1 to $1.0 \mathrm{ng} /$ $\mathrm{mL}$ (experiment $3=0.6 \mathrm{ng} / \mathrm{mL}$; experiment $6=0.8$ $\mathrm{ng} / \mathrm{mL}$ ), which might indicate that our current LFIA design is less accurate within that particular range of
P4 concentrations. From a practical perspective, this is somewhat problematic because differentiating samples in the range of $\mathrm{P} 4$ concentrations around $1 \mathrm{ng} / \mathrm{mL}$ is likely the most valuable. The cutoff commonly used to determine the presence or absence of a functional CL is $1 \mathrm{ng} / \mathrm{mL}$, and based on recent research there may be interest in differentiating samples in the range of 0.3 to $0.5 \mathrm{ng} / \mathrm{mL}$ (Brusveen et al., 2009). Using the latter cutoffs at the time of the GnRH treatment for induction of ovulation before timed AI was better than the traditional $1 \mathrm{ng} / \mathrm{mL}$ cutoff to separate cows with different likelihood of pregnancy after timed AI (Brusveen et al., 2009).

As expected, our platform was able to accurately differentiate plasma samples with $\geq 1$ or $<1 \mathrm{ng} / \mathrm{mL}$ of $\mathrm{P} 4$ (Table 2). We observed high sensitivity $(P<0.0001$; Table 2), which resulted in a low number of false negatives and a high $(P<0.0001)$ negative predictive value. Similarly, albeit of a lower magnitude, specificity and positive predictive value for the LFIA strips were also high (Table $2 ; P<0.01$ ). Average intra-assay coefficient of variation for the 58 samples was $16.0 \%$ (range; 0.5 to 42.8). Collectively, the high sensitivity and specificity of the LFIA-based system resulted in an overall high 
Table 1. Calibration curve features and measures of variability

\begin{tabular}{lccccc}
\hline $\begin{array}{l}\text { Experiment } \\
\text { no. }\end{array}$ & $\begin{array}{c}\text { No. of } \\
\text { samples }\end{array}$ & $\begin{array}{c}\text { P4 range } \\
(\mathrm{ng} / \mathrm{mL})\end{array}$ & $\mathrm{CV}^{2}(\%)$ & $\begin{array}{c}\text { Linear } \\
\text { model R }\end{array}$ & $P$-value \\
\hline 1 & 5 & $0.1-2.0$ & 15.9 & 0.96 & $<0.01$ \\
2 & 5 & $0.1-2.0$ & 6.3 & 0.99 & $<0.01$ \\
3 & 5 & $0.1-2.0$ & 11.1 & 0.53 & 0.16 \\
4 & 5 & $0.1-3.7$ & 13.3 & 0.81 & 0.04 \\
5 & 5 & $0.1-3.7$ & 10.1 & 0.74 & 0.06 \\
6 & 5 & $0.1-3.2$ & 10.0 & 0.42 & 0.24 \\
\hline
\end{tabular}

${ }^{1}$ Six batches of test strips were manufactured to perform 6 independent experiments (i.e., one batch per experiment). For each experiment, a calibration curve was constructed using 5 plasma samples with known concentrations of progesterone.

${ }^{2} \mathrm{CV}=$ average intraassay coefficient of variation.

accuracy $(90 \% ; P<0.0001)$ for classification of plasma samples in groups with $\geq 1$ or $<1 \mathrm{ng} / \mathrm{mL}$ of $\mathrm{P} 4$. Removing the outliers from the calibration curves in experiments $3(\mathrm{n}=1)$ and $6(\mathrm{n}=1)$ increased the $\mathrm{T} / \mathrm{C}$ ratio cutoff value required to differentiate plasma samples with $\geq 1$ or $<1 \mathrm{ng} / \mathrm{mL}$ of $\mathrm{P} 4$, increasing the number of false negatives. Although removing outliers resulted in no major change in specificity $(83 \%, 95 \%$ CI 64 to 94), this change resulted in a reduction in sensitivity from $97 \%$ (95\% CI 82 to 99 ) to $93 \%$ (95\% CI 77 to 99 ), which reduced overall accuracy to $88 \%$ (95\% CI 77 to 95 ). Thus, removing outliers from calibration curves dramatically increased the $\mathrm{R}^{2}$ of the linear models but did not improve overall accuracy of the assay. In addition, the kappa statistic with $(P<0.0001$; kappa $=0.79$, $95 \%$ CI 0.64 to 0.95$)$ and without outliers $(P<0.0001$; kappa $=0.76,95 \%$ CI 0.59 to 0.93 ) was very similar and in both cases represented substantial agreement (Watson and Petrie, 2010), suggesting that, for future experiments, removing one outlier from a calibration curve might not be necessary to improve performance of the LFIA.

The reason for the greater number of false positives than false negatives when implementing the current LFIA design is unclear at the moment. One possible explanation may be cross-reactivity of the antibodies with analytes other than P4. Indeed, manufacturers of the anti-P4 antibody used in the current LFIA report $25 \%$ cross-reactivity with 11-hydroxyprogesterone and $10 \%$ toward 5- $\alpha$-pregnane-3,20 dione, both of which are $\mathrm{P} 4$ metabolites. In addition, all samples that led to false positive outcomes had $\mathrm{P} 4$ levels in the range of 0.2 to $0.8 \mathrm{ng} / \mathrm{mL}$, whereas all samples with $\mathrm{P} 4$ below this range $(\mathrm{n}=18)$ were accurately classified as negative. These results suggest that perhaps our current LFIA design is less accurate to correctly classify samples when $\mathrm{P} 4$ levels are in the range of 0.1 to $1 \mathrm{ng} / \mathrm{mL}$, in particular those with $\mathrm{P} 4$ levels in the range of 0.2 to $0.8 \mathrm{ng} / \mathrm{mL}$. The practical relevance of inaccurately classifying cows as having $\geq 1$ or $<1 \mathrm{ng} / \mathrm{mL}$ of $\mathrm{P} 4$ when they have such circulating P4 levels may depend on the specific use of the assay results. For example, it may be less problematic when the assay is used to assign cows to synchronization of ovulation protocols (i.e., treatment the cow receives may not be optimal but result in acceptable fertility) than when using it to confirm estrus or luteal regression at the end of a timed AI program. The consequences of false positive outcomes are greater for the latter situations (i.e., decide not to inseminate a cow when the cow is truly in estrus or assume failure to regress a CL before timed AI). Given the flexibility of the tool developed, these issues may be circumvented by adapting assay outcomes to its intended use. For example, different $\mathrm{T} / \mathrm{C}$ ratios could be used to classify cows in groups of circulating $\mathrm{P} 4$ levels if the tool is used to confirm estrus or assign cows to synchronization of ovulation protocols based on the presence of a functional CL. A caveat of using circulating $\mathrm{P} 4$ concentrations as the sole method to determine the presence of a functional CL is assuming that circulating concentrations of $\mathrm{P} 4 \geq 1 \mathrm{ng} / \mathrm{mL}$ are always indicative of the presence of a functional CL. It is well known that some cows may have circulating concentrations of $\mathrm{P} 4 \geq 1 \mathrm{ng} / \mathrm{mL}$ due to the presence of a luteal or a partially luteinized follicular cyst capable of producing sufficient $\mathrm{P} 4$ to rise circulating concentrations above the cutoff (Giordano et al., 2016). Thus, further research is necessary to determine the practical implications of misclassifying cows in CL functionality groups based on circulating P4. Although this is uncertain at the moment, we speculate that the effect of misclassifying cows on herd reproductive performance and economics will depend on the type of reproductive management decision made based on results from the LFIA system.

To examine the diagnostic ability of the current LFIA to differentiate plasma samples with $\geq 1$ or $<1 \mathrm{ng} / \mathrm{mL}$ of $\mathrm{P} 4$ without a calibration curve for individual batches, we performed ROC analyses to identify a single cutoff value for $\mathrm{T} / \mathrm{C}$ ratio that could potentially be used for 
A
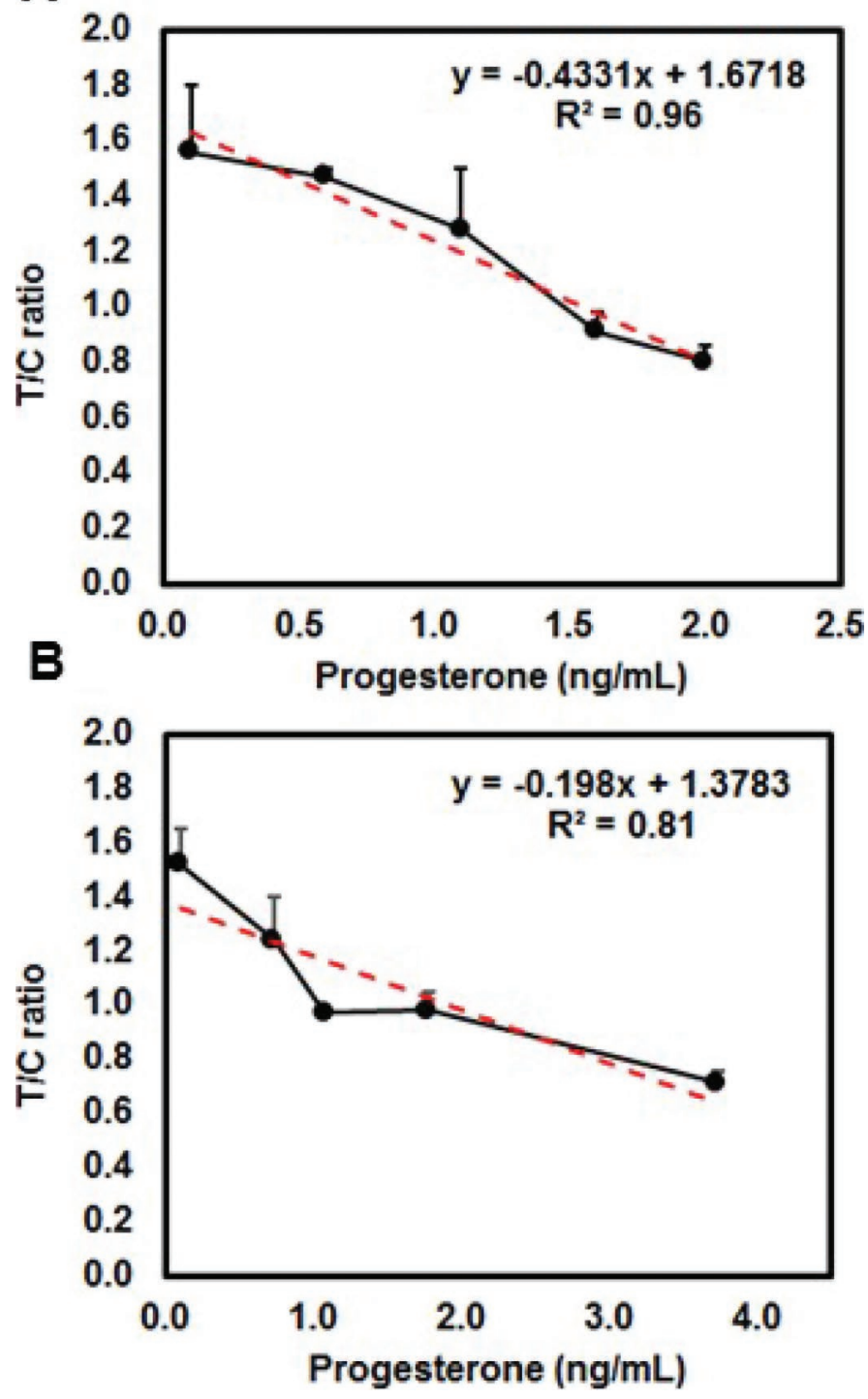

Figure 3. Representative calibration curves (experiments 1 and 4) showing the average test-to-control-line signal ( $\mathrm{T} / \mathrm{C}$ ratio) of the colorimetric signals at various $(\mathrm{n}=5)$ standard $\mathrm{P} 4$ concentrations in bovine plasma. Dotted red line shows linear curve fit. Error bars shown are $\mathrm{SE}, \mathrm{n}=3$.

all batches. To generate the ROC curves, we used the traditional cutoff value (i.e., $1 \mathrm{ng} / \mathrm{mL}$ ) for $\mathrm{P} 4$ concentration for determination of the presence of a functional CL (Ginther et al., 2010). Although there may be physiological conditions under which this cutoff is not necessarily associated with the presence of a functional CL, we used this value because it is commonly used in research and in practice. The optimal cutoff $\mathrm{T} / \mathrm{C}$ ratio selected based on the ROC curve constructed with the $1 \mathrm{ng} / \mathrm{mL}$ cutoff for $\mathrm{P} 4$ resulted in a sensitivity and specificity of $96.5 \%$ (95\% CI 82.2 to 99.9 ) and $79.3 \%$ (95\% CI 60.3 to 92.0 ), respectively (Figure 4 ). The T/C ratio cutoff at which sensitivity and specificity were optimized was $\leq 1.35$. We also examined the area under the curve (AUC) as a summary measure of the overall accuracy of a diagnostic test (Simundić, 2009; Watson and Petrie, 2010). In this case, the AUC indicates the probability that a randomly selected sample obtained from a group of samples with $\mathrm{P} 4$ concentration $\geq 1 \mathrm{ng} /$ $\mathrm{mL}$ would have a higher predicted probability of being classified as high P4 than a randomly chosen sample from a group of samples with $\mathrm{P} 4<1 \mathrm{ng} / \mathrm{mL}$ (Watson and Petrie, 2010). For example, when $\mathrm{AUC}=1$, the test is perfectly accurate, meaning that samples with unknown concentrations of P4 would always be correctly assigned to high or low $\mathrm{P} 4$ groups based on the cutoff of interest. Conversely, if the AUC is equal to 0.5 the test is no better than chance alone at discriminating between the 2 outcomes (Watson and Petrie, 2010), meaning that samples with unknown concentrations of P4 would have a $50 \%$ chance of being incorrectly assigned to the high or low $\mathrm{P} 4$ group. In the present study, the AUC was $0.93(P<0.0001 ; 95 \%$ CI 0.83 to 0.98$)$, which is generally classified as of excellent diagnostic accuracy (Šimundić, 2009). Although the specificity for the ROC to differentiate plasma samples with $\geq 1$ or $<1 \mathrm{ng} / \mathrm{mL}$ of $\mathrm{P} 4$ was lower than that obtained with calibration curves, using a single cutoff value reduces overall complexity of the system for on-farm implementation. In addition, our current LFIA assembly is done manually one batch at a time, significantly increasing variation between batches. Future automated assembly at a commercial scale may significantly reduce variation across batches, which can potentially improve the performance of the LFIA using a single $\mathrm{T} / \mathrm{C}$ ratio cutoff when compared with that obtained with calibration curves.

Overall, results from the ROC analyses showed that sensitivity increased and specificity decreased as the

Table 2. Outcomes of performance for the ability of the lateral flow immunoassay system to differentiate plasma samples with $\geq 1$ or $<1$ $\mathrm{ng} / \mathrm{mL}$ of progesterone

\begin{tabular}{lccl}
\hline Variable $^{1}$ & Value & $95 \%$ CI & $P$-value \\
\hline Sensitivity [\% (n/n)] & $97(28 / 29)$ & 82,99 & $<0.0001$ \\
Specificity [\% (n/n)] & $83(24 / 29)$ & 64,94 & $<0.01$ \\
PPV [\% (n/n)] & $85(28 / 33)$ & 68,95 & $<0.0001$ \\
NPV [\% (n/n)] & $96(24 / 25)$ & 80,99 & $<0.0001$ \\
Accuracy [\% (n/n)] & $90(52 / 58)$ & 79,96 & $<0.0001$ \\
Kappa value & 0.79 & $0.64,0.95$ & $<0.0001$ \\
\hline
\end{tabular}

${ }^{1}$ Six batches of test strips were manufactured to perform 6 independent experiments (i.e., one batch per experiment). To calculate each variable (and respective CI), data of all experiments combined $(\mathrm{n}=$ 58 samples) were used. Confidence intervals and exact tests for sensitivity, specificity, positive predictive value (PPV), negative predictive value (NPV), and accuracy were computed under the null hypothesis that the proportion equals 0.5. For the kappa statistic, the null hypothesis was set to kappa $=0$ (no agreement). 


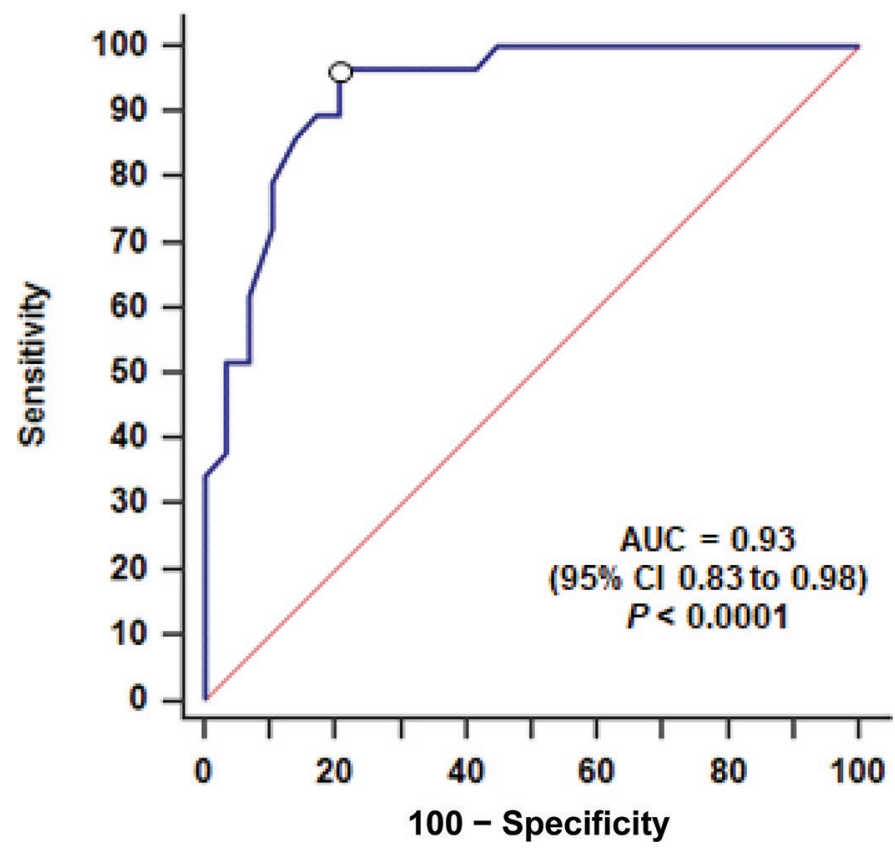

Figure 4. Receiver operating characteristic curve for test-to-control-line signal ( $\mathrm{T} / \mathrm{C}$ ratio) of the lateral flow immunoassay strips and plasma progesterone concentration $\geq 1$ or $<1 \mathrm{ng} / \mathrm{mL}$ as the reference test. The white circle in the left corner of the curve illustrates the optimal sensitivity $(96.5 \%$; $95 \%$ CI 82.2 to 99.9$)$ and specificity $(79.3 \%$; $95 \%$ CI 60.3 to 92.0 ) determined by the receiver operating characteristic analysis. The cutoff $\mathrm{T} / \mathrm{C}$ ratio value at this point was $\leq 1.35$. The area under the curve (AUC) was $0.93(P<0.0001 ; 95 \%$ CI 0.83 to 0.98$)$.

cutoff $\mathrm{T} / \mathrm{C}$ ratio increased (Table 3 ). In practice, different thresholds for $\mathrm{T} / \mathrm{C}$ ratio can be selected to either favor sensitivity or specificity, depending on the intended application of the LFIA system results. For instance, if the intent is to maximize early reinsemination of nonpregnant cows after a previous AI, probably a higher cutoff is more appropriate because we would increase sensitivity and thus reduce the misclassification of cows as nonpregnant when they are truly pregnant. However, if the intent is to assign cows to specific hormonal treatments, a lower cutoff may be more appropriate because we would increase specificity and thus avoid misclassification of cows as having a functional CL present when in fact they lack a functional CL. This is relevant because a very well-documented problem with cows in the Ovsynch protocol for synchronization of ovulation is that cows that lack a functional CL at the time of the $\mathrm{PGF}_{2 \alpha}$ treatment will have reduced fertility when compared with cows with a CL (Giordano et al., 2016). These cows can instead be re-assigned to another synchronization of ovulation protocol designed to increase fertility of cows lacking a functional CL (Wijma et al., 2018). Additional research is needed to confirm that values for sensitivity and specificity can be customized for different applications by modifying the $\mathrm{T} / \mathrm{C}$ ratio cutoff.

Because of the asynchrony in timing of structural and functional luteolysis (i.e., physical disappearance of the CL vs. the cessation of P4 production by luteal cells and metabolism of $\mathrm{P} 4$ ), traditional methods for on-farm determination of functional CL presence (i.e., transrectal palpation and transrectal ultrasonography) usually result in high sensitivity but low specificity. This is due, at least in part, to the fact that luteal tissue can be palpated (rectal palpation) or visualized (transrectal ultrasonography) for days after P4 production ceases (Herzog et al., 2010). As a result, cows are misclassified as having a functional CL when in fact P4

Table 3. Sensitivity and specificity for different test-to-control-line signal (T/C) ratio cutoff points obtained by receiver operating characteristic analysis to differentiate plasma samples with $\geq 1 \mathrm{or}<1 \mathrm{ng} / \mathrm{mL}$ of progesterone with the lateral flow immunoassay system

\begin{tabular}{lcccc}
\hline T/C ratio cutoff & Sensitivity $^{1}(\%)$ & $95 \%$ CI & Specificity $^{1}(\%)$ & $95 \%$ CI \\
\hline$<0.37$ & 0 & $0-12$ & 100 & $88-100$ \\
$\leq 0.77$ & 34 & $18-54$ & 100 & $88-100$ \\
$\leq 0.81$ & 38 & $21-58$ & 97 & $82-100$ \\
$\leq 0.90$ & 52 & $33-71$ & 97 & $82-100$ \\
$\leq 0.92$ & 52 & $33-71$ & 93 & $77-99$ \\
$\leq 1.02$ & 62 & $42-79$ & 93 & $77-99$ \\
$\leq 1.05$ & 72 & $53-87$ & 90 & $73-98$ \\
$\leq 1.08$ & 79 & $60-92$ & 90 & $73-98$ \\
$\leq 1.09$ & 86 & $68-96$ & 86 & $68-96$ \\
$\leq 1.25$ & 90 & $73-98$ & 83 & $64-94$ \\
$\leq 1.26$ & 90 & $73-98$ & 79 & $60-92$ \\
$\leq 1.35^{2}$ & 97 & $82-100$ & 79 & $60-92$ \\
$\leq 1.42$ & 97 & $82-100$ & 59 & $39-77$ \\
$\leq 1.45$ & 100 & $88-100$ & 55 & $36-74$ \\
$\leq 2.52$ & 100 & $88-100$ & 0 & $0-12$ \\
\hline
\end{tabular}

${ }^{1}$ A RIA for progesterone was used as the reference test.

${ }^{2}$ Optimal cutoff indicated by the receiver operating characteristic curve analyses. 
is already below $1 \mathrm{ng} / \mathrm{mL}$ (i.e., false positives). For instance, Kelton et al. (1991) reported that the sensitivity and specificity of transrectal palpation for diagnosing a functional CL were 82.6 and $52.6 \%$, respectively. Similarly, Bicalho et al. (2008) and Sauls-Hiesterman et al. (2020) reported that the sensitivity and specificity for transrectal ultrasonography were approximately 90 and $40 \%$, respectively. Because our LFIA system predicts the presence of a functional CL based on P4 levels rather than rectal palpation of the ovaries or visual observation of luteal tissue by ultrasonography, the number of false positives may be reduced, which may explain the substantially greater specificity compared with reported values for some of the traditional methods to detect the presence of a functional CL. In contrast, our results for specificity, overall accuracy, and interrater agreement are in the same range than previously reported in studies in which determination of a CL by transrectal ultrasonography was optimized by using a cutoff CL diameter rather than strict visualization of luteal tissue (Bicalho et al., 2008; McArt et al., 2010). A caveat of the current LFIA system is that it cannot differentiate the source of P4. Therefore, it will not be possible to differentiate a functional CL from other ovarian structures that may be present on the ovaries and produce $\mathrm{P} 4$ such as luteal or follicular cysts with a partially luteinized wall.

Unlike the traditional methods, our LFIA portable system provides the additional advantage of not requiring expensive equipment or expertise to diagnose CL presence. In addition, if our system ever becomes immediate and cow-side (i.e., no need for sample processing and includes fully automated image processing), then it could potentially be more beneficial than traditional methods because it will not need expert personnel to diagnose CL presence. As for traditional methods, however, our current LFIA system also presents several limitations that need to be addressed [for example, the need to use plasma rather than whole blood and the total time from sample dispensing until results become available $(\sim 18 \mathrm{~min})]$. Thus, future work will focus on further optimizing the performance of our current LFIA design for determination of $\mathrm{P} 4$ concentrations in whole blood samples and strategies to reduce time from sample collection until results become available. In addition, algorithms for automated image processing and determination of $\mathrm{T} / \mathrm{C}$ ratios need to be developed and validated.

\section{CONCLUSIONS}

We developed and demonstrated a simple and novel method for estimating concentrations of P4 in bovine plasma samples from lactating dairy cows. The system consisting of a disposable fluorescence-based LFIA combined with a fluorescence portable imaging device presented high accuracy for differentiation of plasma samples with $\geq 1$ or $<1 \mathrm{ng} / \mathrm{mL}$ of $\mathrm{P} 4$. Additional improvements of this assay system may lead to the development of a rapid, low-cost, cow-side tool for determination of the reproductive status of cattle based on estimation of circulating concentrations of $\mathrm{P} 4$.

\section{ACKNOWLEDGMENTS}

This work was supported by the USDA National Institute of Food and Agriculture, Agriculture and Food Research Initiative Foundational program area priority Nanotechnology for Agricultural and Food Systems project number 2016-08814. Any opinions, findings, conclusions, or recommendations expressed in this publication are those of the authors and do not necessarily reflect the view of the National Institute of Food and Agriculture (NIFA) or the USDA. This research work was also partially supported by the Cornell Initiative for Digital Agriculture. The authors thank Manuel Masello for his assistance designing some of the figures presented in the current manuscript. The authors have not stated any conflicts of interest.

\section{REFERENCES}

Adriaens, I., W. Saeys, T. Huybrechts, C. Lamberigts, L. François, K. Geerinckx, J. Leroy, B. De Ketelaere, and B. Aernouts. 2018. A novel system for on-farm fertility monitoring based on milk progesterone. J. Dairy Sci. 101:8369-8382. https://doi.org/10.3168/ jds.2017-13827.

Barletta, R., P. Carvalho, V. Santos, L. Melo, C. Consentini, A. Netto, and P. Fricke. 2018. Effect of dose and timing of prostaglandin F2o treatments during a Resynch protocol on luteal regression and fertility to timed artificial insemination in lactating Holstein cows. J. Dairy Sci. 101:1730-1736. https://doi.org/10.3168/jds.2017-13628.

Bicalho, R., K. Galvão, C. Guard, and J. Santos. 2008. Optimizing the accuracy of detecting a functional corpus luteum in dairy cows. Theriogenology 70:199-207. https://doi.org/10.1016/j theriogenology.2008.03.015.

Bruinjé, T., and D. Ambrose. 2019. Validation of an automated inline milk progesterone analysis system to diagnose pregnancy in dairy cattle. J. Dairy Sci. 102:3615-3621. https://doi.org/10.3168/ jds.2018-15692.

Brusveen, D., A. Souza, and M. Wiltbank. 2009. Effects of additional prostaglandin F2 $\alpha$ and estradiol-17 $\beta$ during Ovsynch in lactating dairy cows. J. Dairy Sci. 92:1412-1422. https://doi.org/10.3168/ jds.2008-1289.

Friggens, N., M. Bjerring, C. Ridder, S. Højsgaard, and T. Larsen. 2008. Improved detection of reproductive status in dairy cows using milk progesterone measurements. Reprod. Domest. Anim. 43:113-121. https://doi.org/10.1111/j.1439-0531.2008.01150.x.

Galvão, K., M. Frajblat, W. Butler, S. Brittin, C. Guard, and R. Gilbert. 2010. Effect of early postpartum ovulation on fertility in dairy cows. Reprod. Domest. Anim. 45:e207-e211.

Ginther, O., H. Shrestha, M. Fuenzalida, A. Shahiduzzaman, M. Hannan, and M. Beg. 2010. Intrapulse temporality between pulses of a metabolite of prostaglandin F2 $\alpha$ and circulating concentrations of progesterone before, during, and after spontaneous luteolysis 
in heifers. Theriogenology 74:1179-1186. https://doi.org/10.1016/ j.theriogenology.2010.05.018.

Giordano, J., A. Kalantari, P. Fricke, M. Wiltbank, and V. Cabrera. 2012. A daily herd Markov-chain model to study the reproductive and economic impact of reproductive programs combining timed artificial insemination and estrus detection. J. Dairy Sci. 95:54425460. https://doi.org/10.3168/jds.2011-4972.

Giordano, J., M. Thomas, G. Catucuamba, M. Curler, M. Masello, M. Stangaferro, and R. Wijma. 2016. Reproductive management strategies to improve the fertility of cows with a suboptimal response to resynchronization of ovulation. J. Dairy Sci. 99:29672978. https://doi.org/10.3168/jds.2015-10223.

Hankele, A. K., K. Rehm, J. Bérard, G. Schuler, L. Bigler, and S. E. Ulbrich. 2020. Progestogen profiling in plasma during the estrous cycle in cattle using an LC-MS based approach. Theriogenology 142:376-383. https://doi.org/10.1016/j.theriogenology.2019.10 .005 .

Herzog, K., M. Brockhan-Lüdemann, M. Kaske, N. Beindorff, V. Paul, H. Niemann, and H. Bollwein. 2010. Luteal blood flow is a more appropriate indicator for luteal function during the bovine estrous cycle than luteal size. Theriogenology 73:691-697. https://doi.org/ 10.1016/j.theriogenology.2009.11.016.

Kelton, D. F., K. E. Leslie, W. G. Etherington, B. N. Bonnett, and J. S. Walton. 1991. Accuracy of rectal palpation and of a rapid milk progesterone enzyme-immunoassay for determining the presence of a functional corpus luteum in subestrous dairy cows. Can. Vet. J. $32: 286-291$.

Landis, J. R., and G. G. Koch. 1977. The measurement of observer agreement for categorical data. Biometrics 33:159-174. https://doi .org/10.2307/2529310.

Lu, Z., D. O'Dell, B. Srinivasan, E. Rey, R. Wang, S. Vemulapati, S. Mehta, and D. Erickson. 2017. Rapid diagnostic testing platform for iron and vitamin A deficiency. Proc. Natl. Acad. Sci. USA 114:13513-13518. https://doi.org/10.1073/pnas.1711464114.

Masello, M., M. Scarbolo, M. V. Schneck, M. M. Perez, E. M. Schillkowsky, E. M. Sitko, F. Sosa Hernandez, E. M. Cabrera, R. M. Rossi, and J. O. Giordano. 2020. Intravaginal instillation of prostaglandin $\mathrm{F} 2 \alpha$ was as effective as intramuscular injection for induction of luteal regression in lactating dairy cows. J. Dairy Sci. 103:2743-2755. https://doi.org/10.3168/jds.2019-17589.

McArt, J., L. Caixeta, V. Machado, C. Guard, K. Galvao, O. Sá Filho, and R. Bicalho. 2010. Ovsynch versus Ultrasynch: Reproductive efficacy of a dairy cattle synchronization protocol incorporating corpus luteum function. J. Dairy Sci. 93:2525-2532. https://doi .org/10.3168/jds.2009-2930.

NAHMS. 2018. Dairy 2014, Part III: Reference of Dairy Cattle Health and Management Practices in the United States, 2014. \#696.0218. Centers for Epidemiology and Animal Health, USDA, Animal and Plant Health Inspection Service, Veterinary Services, Fort Collins, $\mathrm{CO}$.

Nakami, W., V. Tsuma, K. Milkey, M. Dickerson, M. Wong, H. Mutembei, J. Muthee, O. Odipo, and W. Ngetich. 2017. Lateral flow immunoassay for whole blood progesterone detection as a tool for assessment of reproductive status in cattle. Int. J. Vet. Sci. 6:19-25.

Posthuma-Trumpie, G. A., A. van Amerongen, J. Korf, and W. J. van Berkel. 2009. Perspectives for on-site monitoring of progesterone. Trends Biotechnol. 27:652-660. https://doi.org/10.1016/j.tibtech 2009.07.008

Sajid, M., A.-N. Kawde, and M. Daud. 2015. Designs, formats and applications of lateral flow assay: A literature review. J. Saudi Chem. Soc. 19:689-705. https://doi.org/10.1016/j.jscs.2014.09.001.
Sauls-Hiesterman, J., B. Voelz, and J. Stevenson. 2020. A shortened resynchronization treatment for dairy cows after a nonpregnancy diagnosis. Theriogenology 141:105-112. https://doi.org/10.1016/j .theriogenology.2019.09.013.

Schneider, C. A., W. S. Rasband, and K. W. Eliceiri. 2012. NIH Image to ImageJ: 25 years of image analysis. Nat. Methods 9:671-675. https://doi.org/10.1038/nmeth.2089.

Šimundić, A.-M. 2009. Measures of diagnostic accuracy: Basic definitions. EJIFCC 19:203-211.

Skenandore, C., A. Pineda, J. Bahr, A. Newell-Fugate, and F. Cardoso. 2017. Evaluation of a commercially available radioimmunoassay and enzyme immunoassay for the analysis of progesterone and estradiol and the comparison of two extraction efficiency methods. Domest. Anim. Endocrinol. 60:61-66. https://doi.org/10.1016/j .domaniend.2017.03.005.

Srinivasan, B., D. O'Dell, J. L. Finkelstein, S. Lee, D. Erickson, and S. Mehta. 2018. ironPhone: Mobile device-coupled point-of-care diagnostics for assessment of iron status by quantification of serum ferritin. Biosens. Bioelectron. 99:115-121. https://doi.org/10 .1016/j.bios.2017.07.038.

Stevenson, J. 2019. Spatial relationships of ovarian follicles and luteal structures in dairy cows subjected to ovulation synchronization: Progesterone and risks for luteolysis, ovulation, and pregnancy. J. Dairy Sci. 102:5686-5698. https://doi.org/10.3168/jds.2018-16036.

Tisone, T. C., and B. O'Farrell. 2009. Manufacturing the next generation of highly sensitive and reproducible lateral flow immunoassay. Pages 131-156 in Lateral Flow Immunoassay. Humana Press, Totowa, NJ.

Waldmann, A., and A. Raud. 2016. Comparison of a lateral flow milk progesterone test with enzyme immunoassay as an aid for reproductive status determination in cows. Vet. Rec. 178:260. https:// doi.org/10.1136/vr.103605.

Watson, P., and A. Petrie. 2010. Method agreement analysis: A review of correct methodology. Theriogenology 73:1167-1179. https://doi .org/10.1016/j.theriogenology.2010.01.003.

White, R., M. Brady, J. Capper, J. McNamara, and K. Johnson. 2015. Cow-calf reproductive, genetic, and nutritional management to improve the sustainability of whole beef production systems. J. Anim. Sci. 93:3197-3211. https://doi.org/10.2527/jas.2014-8800.

Wijma, R., M. Pérez, M. Masello, M. Stangaferro, and J. Giordano. 2018. A resynchronization of ovulation program based on ovarian structures present at nonpregnancy diagnosis reduced time to pregnancy in lactating dairy cows. J. Dairy Sci. 101:1697-1707. https://doi.org/10.3168/jds.2017-13489.

Wilsdorf, L., D. Keisler, S. Poock, W. Lamberson, R. Escalante, and M. Lucy. 2016. Test for nonpregnancy in dairy cows based on plasma progesterone concentrations before and after timed artificial insemination. J. Dairy Sci. 99:5858-5865. https://doi.org/10 $.3168 / j d s .2016-10864$.

Xu, C., W. Yang, C. Xia, L. Wu, and H. Zhang. 2016. Development of a competitive lateral flow immunoassay for progesterone in dairy cows' milk. Med. Weter. 72:494-497. https://doi.org/10.21521/mw .5546 .

\section{ORCIDS}

M. Masello @ https://orcid.org/0000-0001-9573-1786

J. Gavalchin $\odot$ https://orcid.org/0000-0002-7611-9468

J. O. Giordano @ https://orcid.org/0000-0003-1455-6811 